\title{
Reflexões sobre embalagens de alimentos e sustentabilidade
}

As embalagens de alimentos apresentam indiscutível importância na vida moderna para viabilização dos produtos à população. Entretanto, a rotina atual de consumo juntamente com as novas tecnologias tem proporcionado aumento na produção de resíduos. Os materiais que compõem as embalagens podem permanecer por muito tempo no ambiente. Ao passo que a quantidade de embalagem consumida aumenta, há consequente aumento da geração de resíduos e, por fim, empresas são pressionadas a assumir responsabilidade por todo o ciclo de vida dos produtos. Neste contexto, percebe-se que os consumidores têm alterado hábitos alimentares e decisões de compras priorizando aspectos de uma vida mais saudável. Estas ações consequentemente promovem mudanças no mercado de embalagens. Embalagens geram impactos ambientais e estão intimamente ligados ao desperdício de alimentos e geração de resíduos, e os responsáveis por mudanças massivas são os consumidores e suas atitudes frente a esse assunto. Uma forma de contribuir para redução na geração de resíduos é conhecer o material que compõe as embalagens e buscar escolher aqueles que provocam menor impacto. Questões ambientais geram grande influência sobre o comportamento dos consumidores, o que é interessante para as empresas e pode se tornar um diferencial. No entanto, para haver mudança é preciso que o consumidor reconheça as informações e se sinta motivado para realizar ações positivas, vendo o impacto por elas gerado.

Palavras-chave: Sustentabilidade ambiental; Embalagens; Alimentos; Consumidores.

\section{Reflections on food packaging and sustainability}

Food packaging has undoubted importance in modern life for making products available to the population. However, the current consumption routine togethe with new technologies has provided an increase in waste production. The materials that make up the packaging can remain in the environment for a long time. As the amount of packaging consumed increases, there is a consequent increase in the generation of waste and, finally, companies are under pressure to assume responsibility for the entire life cycle of the products. In this context, it is clear that consumers have changed eating habits and purchasing decisions, prioritizing aspects of a healthier life and consequently promoting changes in the packaging market. One way to contribute to reducing the generation of waste is to know the material that makes up the packaging and try to choose those that cause less environmental impact. Packaging generates environmental impacts and is closely linked to food waste and waste generation, and those responsible for massive changes are consumers and their attitudes towards this issue. Environmental issues generate great influence on consumer behavior, which is interesting for companies and can become a differentiator. However, in order to change, the consumer needs to recognize the information and feel motivated to take positive actions, seeing the impact generated by them.

Keywords: Environmental sustainability; Packaging; Foods; Consumers.

Topic: Desenvolvimento, Sustentabilidade e Meio Ambiente

Reviewed anonymously in the process of blind peer
Received: 03/03/2021

Approved: 26/03/2021
Jessica Santana Carvalho (iD)

Universidade Federal do Espírito Santo, Brasil

http://lattes.cnpq.br/4902540386910144

http://orcid.org/0000-0001-9173-2298

jscarvalho29@gmail.com

Jhenifer de Souza Couto Oliveira (iD)

Universidade Federal do Espírito Santo, Brasil

http://orcid.org/0000-0002-4064-7912

ihenifersco@hotmail.com

Jackline Freitas Brilhante de São José (id

Universidade Federal do Espírito Santo, Brasil

http://lattes.cnpq.br/9686717495086118

http://orcid.org/0000-0002-4637-0299

jackline.jose@ufes.br
Referencing this:

JOSÉ, J. F. B. S.; OLIVEIRA, J. S.; CARVALKHO, J. S.. Reflexões sobre embalagens de alimentos e sustentabilidade. Revista Ibero Americana de Ciências Ambientais, v.12, n.3, p.586-597, 2021. DOI: http://doi.org/10.6008/CBPC2179-6858.2021.003.0047 


\section{INTRODUÇÃO}

Segundo a Associação Brasileira de Embalagem (ABRE), embalagem é uma envoltura ou recipiente que contém produtos temporariamente, individualmente ou em unidades, e que tem a função de protegêlo e ampliar o tempo de armazenamento de modo a viabilizar a distribuição, identificação e consumo (ABRE, 2018). A resolução RDC no 91, de 11 de maio de 2001 define embalagem de alimentos como o artigo que está em contato direto com os alimentos e é destinado a contê-los, desde a fabricação até o momento de aquisição pelo consumidor, com intuito de protegê-los de possíveis agentes externos, alterações, contaminações e adulterações (BRASIL, 2001). Em outra definição, o Ministério do Meio Ambiente (MMA) ressalta que a embalagem é essencial para proteção dos produtos durante as etapas de distribuição, armazenamento, comercialização, manuseio e consumo (BRASIL, 2018). Segundo Lautenschlager (2001), o conceito de embalagem irá variar conforme a perspectiva em que é observada.

Atualmente, além das funções já mencionadas, as embalagens de alimentos têm intuito de estimular o desejo de compra e comunicar com o consumidor. Dessa forma, é indiscutível a importância das embalagens na vida moderna para viabilização dos produtos à população. Entretanto, a rotina atual de consumo juntamente com as novas tecnologias tem proporcionado aumento na produção de resíduos. Os materiais que compõem as embalagens podem permanecer por muito tempo no ambiente (LANDIM et al., 2015). Sendo assim, no processo de desenvolvimento de um sistema produto-embalagem é necessário analisar as diversas etapas do impacto ambiental e econômico que são intrínsecos às embalagens e em seu ciclo de vida (KARASKI et al., 2016).

À medida que a quantidade de embalagem consumida aumenta, as empresas são pressionadas a assumir responsabilidade por todo o ciclo de vida dos produtos. Assim, cresce o interesse em embalagens ecologicamente corretas e a busca pelo uso de materiais recicláveis como constituintes de embalagens (KLAIMAN et al., 2016). Dessa forma, a adoção de embalagens e processos mais sustentáveis pelas empresas pode se tornar um atrativo aos consumidores (LANDIM et al., 2015). Entretanto, é preciso refletir se os consumidores conhecem as características dos materiais que compõem as embalagens dos alimentos bem como quais são os impactos ambientais deles. Nesse contexto, a presente revisão de literatura visa discutir a relação das embalagens de alimentos com a sustentabilidade permeando o conhecimento e percepções dos consumidores quanto a implicação destes materiais ao meio ambiente.

\section{METODOLOGIA}

O presente artigo consiste numa revisão sobre embalagens de alimentos com o intuito de avaliar os materiais comumente utilizados na constituição das mesmas bem como avaliar seus impactos ambientais. Além disso, foi feito um levantamento quanto às pesquisas e avaliações de materiais considerados como sustentáveis na composição das embalagens para alimentos. 


\section{DISCUSSÃO TEÓRICA}

\section{Embalagens de alimentos}

O crescimento populacional e o aumento do número de pessoas que vivem em áreas urbanas faz com que seja necessária a ampliação na produção de alimentos e o adequado transportes destes aos consumidores. A embalagem de alimentos deve garantir atender aos requisitos de proteção, comercialidade e logística (VITALE et al., 2018; ABEJÓN et al., 2020; DILUCIA et al., 2020). Trata-se de um invólucro ou recipiente ou qualquer outra forma de acondicionamento, removível ou não, destinada a proteger, especificamente ou não, matérias-primas, produtos semielaborados ou produtos acabados (BRASIL, 2018).

A embalagem é um item indispensável para indústria de alimentos pois a ela são atribuídas diversas funções, sendo indiscutível sua importância na vida moderna para viabilização dos produtos à população. Dentre as funções elementares que a embalagem inclui a proteção, conservação, informação e conveniência no uso do produto são inseparáveis. No quesito conservação do produto, o intuito é manter qualidade e segurança, contra a deterioração causada por micro-organismos, por agentes químicos ou por ações mecânicas e/ou físicas (ABEJÓN et al., 2020). Além disso, a embalagem, por permitir acesso à informação, é primordial aos consumidores (BARÃO, 2011; JORGE, 2013; VITALE et al., 2018). Somado a estas, apresenta funções secundárias que tem despertado interesse no mercado como rastreabilidade, conveniência e praticidade. Sendo assim, a embalagem deve atender tanto as demandas do consumidor quanto às exigências da indústria (MARSH et al., 2007). Para isso a inovação é necessária de modo a permitir a mudança tecnológica que estará no processo de fabricação ou no produto final em busca de permanência em um mercado competitivo, dinâmico e globalizado que recusa uniformidade (CABRAL et al., 2015; GONÇALVES et al., 2016). Esses processos de inovação devem ser realizados na fase de projeção de uma embalagem, onde o desenvolvimento é a partir da identificação das prioridades e/ou necessidades do consumidor ou necessidades favoráveis encontradas pelo marketing; meio vastamente usado para atrair o consumidor e facilitar a compra do produto (CABRAL et al., 2015; LANDIM et al., 2015).

De acordo com a Associação Brasileira de Embalagens (ABRE), há vários tipos de embalagens e cada uma com diversas funcionalidades que só dependerá do que se almeja para o produto. Deve-se levar em conta fatores como o mercado, a vida útil, e capacidade de proteger o produto. Somam-se a estes fatores ainda aspectos técnicos, estéticos, ambientais, mercadológicos, econômicos, regulatórios de legislação e certificações e aspectos de funcionalidade para o desenvolvimento de uma embalagem (BARÃO, 2011; ABRE, 2018)

Quanto à estrutura das embalagens para fins alimentícios podem ser apresentadas em três níveis que são denominados, a saber: primária, secundária e terciária ou de transporte (JORGE, 2013). As embalagens primárias são aquelas que entram em contato direto com o alimento, com intuito de conservar e conter o produto (BARÃO, 2011; JORGE, 2013). As embalagens secundárias entram em contato com as embalagens primárias, e são como suporte de informação ao consumidor. Já as embalagens terciárias agrupam várias embalagens tanto primárias quanto secundárias, sendo responsável pela proteção do 
produto durante o transporte, e o tipo de embalagem dependerá de aspectos como, o custo, a paletização e, a natureza da embalagem individual (BARÃO, 2011; JORGE, 2013). Deste modo, como pode-se perceber, um produto alimentício adquirido pelo consumidor pode conter várias embalagens diferentes. Dessa forma, proporciona maior volume de resíduos gerados. Além disso, as diversas funções das embalagens, por conta do marketing ou estética dos produtos, aliados ao maior poder aquisitivo dos consumidores como também a mudança dos sistemas de distribuição e compra de produtos, impulsionam a produção excessiva de materiais usados somente no mesmo item, que gera elevada quantidade de resíduos sólidos (LANDIM et al., 2015; FERRAZ, 2015).

No que diz respeito aos materiais que comumente são utilizados têm-se: plástico, metal, vidro, materiais compostos e celulósicos.

Os principais requisitos para materiais a serem utilizados em embalagens são apresentarem boa propriedade de barreira ao vapor de água e oxigênio, bom desempenho mecânico e transparência. Deste modo, plásticos dominam o mercado de embalagens (SANGRONIZ et al., 2019). De acordo com a ABRE (2019), os plásticos representam a maior parcela no valor da produção, correspondente a $41 \%$ do total das embalagens produzidas no país. O uso dos plásticos é amplamente difundido devido às diversas possibilidades de aplicações aliadas ao baixo custo, peso leve e alto desempenho, juntamente com boa processabilidade. É esperado que até 2050, a produção de embalagens plásticas excederá 250 milhões toneladas métricas. Apesar da maioria dos plásticos empregados nas embalagens ser utilizada por menos de uma semana, a prolongada durabilidade no meio ambiente gera crescimento destes materiais como resíduos poluentes. Esse crescimento, junto com o fato que a grande maioria dos polímeros sintéticos são projetados para desempenho e durabilidade, mas não para degradabilidade e reciclabilidade, trouxe milhões de toneladas de acumulação de plástico nos oceanos e aterros sanitários (WEF, 2016; SANGRONIZ et al., 2019). Os materiais amplamente utilizados são poli (tereftalato de etileno) (PET), polietileno (PE) e polipropileno (PP). Mesmo com a adoção de práticas atuais de reciclagem, estima-se que quase $95 \%$ do valor dos materiais de embalagem de plástico não sejam retidos para usos subsequentes, o que representa perda anual de US \$ 80-120 bilhões para a economia (WEF, 2016; SANGRONIZ et al., 2019). A preocupação com o uso deste material, está relacionada ainda ao uso de recursos não renováveis.

Outro tipo de embalagens também utilizadas em alimentos são as embalagens metálicas. As embalagens metálicas representam 19\% no valor de produção no setor de embalagens (ABRE, 2019). Estas conferem propriedades de proteção mecânica, característica de barreira, reciclagem e formabilidade. Latas de metal, quando são fechadas hermeticamente, possibilitam a aplicação de altas e baixas temperaturas em etapas do processamento de alimentos. Além disso, esse material oferece proteção à luz, umidade, odores e proteção ao acesso de parasitas e microrganismos (LANDIM et al., 2015; DESHWAL et al., 2019). Os metais mais utilizados pela indústria de alimentos para a composição de embalagens são o aço e o alumínio (FELLOWS, 2006; LANDIM et al., 2015; DESHWAL et al., 2019). As embalagens de aço são feitas de óxido de ferro e tratadas com camadas de cromo ou estanho para evitar processos de oxidação quando em contato com o ar. Apresentam alta resistência mecânica, maior segurança durante o processo de esterilização e são 
recicláveis e degradáveis. Porém, este material pode permanecer até 100 anos no ambiente quando descartados (LANDIM et al., 2015). O alumínio também é utilizado em embalagens de alimentos e bebidas sendo aplicado na fabricação de latas, papel alumínio, e papel ou plásticos laminados ou como filmes metalizados. Este material é leve, impermeável a luz, umidade e odores, maleável, alta relação resistência/peso e resistência à corrosão. Sua degradação na natureza pode demorar de 100 a 500 anos, por isso a importância de ser reciclado (FELLOWS, 2006; LANDIM et al., 2015). Os diferentes caminhos que estes materiais podem ter como reciclagem, aterro e combustão para recuperação de energia são utilizados no intuito de reduzira o volume de resíduos de embalagens de metal e seus efeitos adversos (DESHWAL et al., 2019; WEF, 2016).

Embalagens de vidro também são aplicadas em alimentos. Trata-se de um material que é proveniente da combinação de areia, barrilha, calcário e cacos de vidro em diferentes proporções que são fundidos a $1350^{\circ} \mathrm{C}$ a $1600^{\circ} \mathrm{C}$, fato que permite a moldagem em diferentes formas e tamanhos. Este tipo de embalagem, por ser inerte, traz segurança ao consumidor no que diz respeito a contaminação dos alimentos. Além disso, apresenta características como impermeabilidade a gases e vapor d'agua, praticidade, versatilidade, transparência e proteção à luz (pois permite variações de cor) no caso de produtos sensíveis a este fator (FELLOWS, 2006; LANDIM et al., 2015). Em contrapartida, são materiais pesados e delicados, o que implica em maio custo para o transporte. Segundo a ABRE, o vidro contribui com $6 \%$ no valor de produção de embalagens no Brasil (ABRE, 2019). Apesar do seu tempo de degradação total no ambiente ser indeterminado, seu impacto no ambiente se torna menor por ser completamente reciclável e reutilizável.

E, por fim, as embalagens celulósicas também podem ser utilizadas pela indústria de alimentos e estas podem dar origem as embalagens de papelão e papel. Este material apresenta vantagens como apresentação em diferentes espessuras e formatos, permite combinação com outros materiais, favorece a impressão, baixo peso, resistência a baixas temperaturas e reciclabilidade. Entretanto, apresentam desvantagens como baixa resistência mecânica, baixa barreira e falta de inercia. De acordo com Jorge (2013), o tempo médio de degradação de papel e caixa de papelão são de 3 a 6 meses e no mínimo 6 meses, respectivamente.

Ao escolher a embalagem a ser utilizada deve considerar a manutenção da qualidade sensorial e higienicossanitária dos alimentos comercializados (ABEJÓN et al., 2020; VITALE et al., 2018). Quando isso não é atendido, há possibilidade de desperdício de alimento e geração de resíduos, o que implica em preocupação no contexto ambiental, econômico e social (ABEJÓN et al., 2020).

\section{Geração de resíduos sólidos}

De acordo com a Associação Brasileira de Normas Técnicas - ABNT por meio da NBR 10004, resíduos sólidos são aqueles nos estados sólido e semissólido que resultam de atividades da comunidade de origem industrial, doméstica, hospitalar, comercial e agrícola (ABNT, 2004). De acordo com o Panorama dos Resíduos Sólidos 2018/2019, elaborado pela Associação Brasileira das Empresas de Limpeza Pública (ABRELPE), no Brasil, foram produzidos 79 milhões de toneladas de resíduos no ano de 2018 , sendo que $92 \%$ foram 
coletados e destes 59,5\% receberam destinação adequada nos aterros sanitários (ABRELPE, 2019). Geralmente, os resíduos são compostos por matéria orgânica biodegradável ou não biodegradável (plásticos) e de matéria inorgânica não degradável (LANDIM et al., 2015).

As alterações nos hábitos alimentares e em decisões de compras, de modo a valorizar aspectos de uma vida mais saudável também afetam o mercado de embalagens. Portanto, as empresas devem se atentar para as mudanças e consequentemente buscam implementá-las no momento de escolher a embalagem de seu produto (EMBALAGEM \& CIA, 2001, citado por GONÇALVES et al., 2008; GONÇALVES et al., 2016). Segundo Landim et al. (2015), a embalagem é um fator essencial para mensurar a atividade econômica pois se utiliza dos dados de consumo de embalagens pela população como parâmetros para verificar o nível de desenvolvimento e avanços econômicos desses países. Assim, o adequado desenvolvimento será alcançado com uso responsável de naturais e atendimento aos anseios econômicos. Deste modo, pode-se obter benefícios para ambos os aspectos, tornando, então, sustentável (LANDIM et al., 2015).

Entretanto, a rotina atual de consumo juntamente com as novas tecnologias tem proporcionado aumento na produção de resíduos. Os materiais que compõem as embalagens podem permanecer por muito tempo no ambiente (LANDIM et al., 2015; DESHWAL et al., 2019). Dessa forma, o sistema-produtoembalagem deve ser avaliado para desenvolver embalagens dentro de uma economia circular, onde o impacto gerado pelo ciclo de vida do mesmo é considerado (KARASKI et al., 2016).

Reduzir o desperdício de alimentos e aumentar a eficiência dos recursos tornaram-se metas mundiais, conforme destacado pelo objetivo número 12 de Desenvolvimento Sustentável das Nações Unidas os quais ressaltam a necessidade de garantir padrões responsáveis de consumo e produção (UNITED NATIONS, 2019). Resíduos de alimentos contabilizam cerca de 1,3 bilhão de toneladas no mundo e representam 7\% das emissões de gases de efeito estufa (UNITED NATIONS, 2019). Neste contexto, a embalagem ajuda a reduzir o desperdício de alimentos pois protege os alimentos e ocasionando redução de perdas e prolongando sua vida útil (VERGHESE et al., 2013). Apesar do seu papel importante para a conservação e armazenamento de alimentos, as embalagens tornaram-se um problema ambiental, principalmente os plásticos de uso único, devido à sua dependência de recursos de combustíveis fósseis e falta de práticas adequadas de gerenciamento de resíduos.

De acordo com Jorge (2013), ao discutir a gestão dos resíduos de embalagem, existe uma hierarquização dos métodos de gestão, baseados nos 3Rs da sustentabilidade, a saber: Redução na origem, Reutilização e Reciclagem. Segundo este autor, há dificuldades para serem superadas, mas a reciclagem é ainda uma das formas mais apropriadas para tratar a embalagem já utilizada e que será descartada.

A avaliação do ciclo de vida, que trata do cálculo dos impactos ambientais causados por um determinado produto, método ou atividade, permite indicar opções que causem menor impacto no meio ambiente. Neste contexto, sabe-se que embalagens podem afetar drasticamente o ambiente devido ao tempo necessário para serem totalmente degradadas e para serem submetidas aos processos de reciclagem (LANDIM et al., 2015). Assim, uma forma de contribuir para redução na geração de resíduos é conhecer o material que compõe as embalagens e buscar escolher aqueles que provocam menor impacto ambiental. 
As embalagens plásticas representam $26 \%$ do total de plásticos utilizados e cerca de $72 \%$ desses materiais são perdidos atualmente, com $40 \%$ terminando em aterros e $32 \%$ nos oceanos e áreas urbanas. Além disso, a produção total de plásticos representa $6 \%$ do petróleo mundial consumo. Embora a taxa de reciclagem de plástico tenha aumentado, apenas $14 \%$ são reciclados e, após tratamento adicional, apenas $5 \%$ do custo do material é retido (EMF, 2017)

\section{Embalagens com menor impacto ambiental}

A Lei no 12.305/10 que trata da Política Nacional de Resíduos Sólidos trouxe à tona o estímulo a prevenção e a redução da geração de resíduos (BRASIL, 2010). Essa lei propõe como objetivos a não geração, redução, reutilização, reciclagem e tratamento dos resíduos sólidos, bem como a acondicionamento final ambientalmente adequada dos rejeitos. Deste modo, para alcançar estes objetivos deve-se adotar hábitos de consumo mais sustentáveis, incentivo às práticas de reciclagem, reutilização de resíduos sólidos e destino apropriado dos rejeitos por meio de compostagem (BRASIL, 2010; LANDIM et al., 2015).

Nas últimas duas décadas têm-se discutido estratégias para promover a redução de resíduos oriundos de embalagens (SANGRONIZ et al., 2019). Os impactos ambientais das embalagens de alimentos dependem do material utilizado e de suas características. A definição do material e do design da embalagem são aspectos fundamentais sob ponto de vista da sustentabilidade e influenciarão no desempenho geral do produto (SIMON et al., 2016; ABEJÓN et al., 2020).

A embalagem sustentável a partir de recursos renováveis tem sido amplamente estudada para a substituição de polímeros sintéticos. Os bioplásticos são um mercado nascente que captura o mercado de plásticos a uma taxa de crescimento de $30 \%$ ao ano (ROMANI et al., 2017). Um amplo espectro de materiais pode ser usado para a produção de polímeros biodegradáveis, como proteínas, polissacarídeos e lipídios (DEBIAGI et al., 2014; ROMANI et al., 2017). Assim, ao pensar-se em alternativas para as embalagens já existentes, é fundamental o estudo do ciclo de vida destes materiais.

Dentre as opções estudadas há o uso de polímeros biodegradáveis como ácido polilático (PLA) ou poli (3-hidroxibutirato) (PHB). Polímeros biodegradáveis são excelentes alternativas às embalagens convencionais à base de petróleo pois são derivados de fontes biorenováveis e podem ser degradados enzimaticamente ou hidroliticamente. No entanto, a alta permeabilidade no caso do PLA e a fraca resistência mecânica propriedades no caso de PHB (um material quebradiço), mais a falta de alta reciclabilidade química são fatores que limitam sua aplicação (SANGRONIZ et al., 2019).

O amido pode ser usado para desenvolver filmes devido à sua alta disponibilidade, baixo custo e sua capacidade de formar matrizes poliméricas inodoras e incolores com baixa permeabilidade ao oxigênio. Além disso, a extração de amido de grãos de arroz quebrados, por exemplo, é uma alternativa para agregar valor a esse material, transformando-o em produto com interesse industrial para a produção de embalagens biodegradáveis para alimentos, contribuindo positivamente para reduzir o problema da poluição ambiental (ROMANI et al. 2017)

Sangroniz et al. (2019) avaliaram uma classe de plásticos biorenováveis e degradáveis, com base em 
copolímeros de $\gamma$-butirolactona, com características de permeabilidade e alongamento a ruptura compatíveis a polímeros comumente usados e com propriedades mecânicas e de transporte superiores aos dos plásticos de base biológica mais promissores. Estes autores destacaram que esses copolímeros representam uma classe promissora de materiais que podem ser implementados em embalagens com possibilidade de um ciclo de vida fechado por meio de sua degradabilidade ou reciclabilidade química, fato que contribui para redução ou eliminação de poluentes plásticos.

\section{Conhecimentos e práticas dos consumidores quanto as características das embalagens de alimentos}

Consumidores e a cadeia de produção de alimentos demandam cada vez mais produtos oriundos de processos que geram pouco ou nenhum resíduo e que produzido de modo mais sustentáveis (FORTUNATI et al., 2018). Nesse processo de busca por menor geração de impacto ambiental, cabe ressaltar que os consumidores também têm papel essencial quanto a exigência de embalagens sustentáveis, pois são eles que decidem quais produtos irão comprar e consumir (ECYCLE, 2018). Ao elaborar uma embalagem, deve-se considerar o pós-consumo incentivando tecnologias de revalorização, reciclagem da embalagem e as coletas seletivas. Isto demostra a importância na escolha de embalagens de modo a não comprometer as cadeias de revalorização existentes (KARASKI et al., 2016). Tais informações adicionais podem predispor os consumidores a comprar embalagens recicláveis, pois eles consideram positiva a aquisição de um produto com estas características (KLAIMAN et al., 2016).

Atualmente as questões ambientais geram grande influência sobre o comportamento dos consumidores, o que é interessante para as empresas e pode se tornar um diferencial (TAMASHIRO et al., 2013). De acordo com Grunet et al. (2018), os rótulos de sustentabilidade são ensejos para as escolhas alimentares dos consumidores. Entretanto, isso não implicará na sua utilização real, pois tal fato dependerá da motivação do consumidor para fazer uso dessas informações e se têm entendimento sobre os rótulos (GRUNET et al., 2018; FERRAZ, 2015). Atualmente, as empresas têm se adaptado frente à crescente consciencialização ambiental dos consumidores, com uso de símbolos, informações sobre a composição da embalagem e o destino mais adequado quando a mesma se torna resíduo (FERRAZ, 2015). A embalagem sustentável deve trazer as respostas esperadas tanto no âmbito ambiental, reduzindo materiais, recursos, energia quanto na proteção dos alimentos de forma eficiente (LICCIARDELLO, 2017).

Segundo Tseng et al. (2020), transição de consumo sustentável (TCS) é um processo no qual deixa-se de ser insustentável e torna-se sustentável. Para que isso ocorra é necessário envolvimento de uma mudança de pontos de vista, posições e táticas pelos consumidores e reguladores autoridades, concentrando-se simultaneamente na qualidade de vida. TCS é complexa devido à natureza do comportamento do consumidor (DONG et al., 2020) e que alterá-lo é fundamental para promover transições em direção a práticas de consumo sustentável (TSENG et al., 2020)

Vega-Zamora et al. (2019) ressaltaram que os consumidores têm falta de confiança e conhecimento sobre produtos sustentáveis. Para resolver esse problema, alguns fabricantes desenvolveram produtos e embalagens sustentáveis, e o governo implementou políticas e regulamentos ambientais. Se produtos e 
embalagens sustentáveis alcançam os consumidores depende consideravelmente do processo de compra dos produtos certos para então orientar sua consciência ambiental.

Cortês et al. (2016) ao realizarem pesquisa com jovens universitários brasileiros e portugueses verificaram que há tendência clara em relação de preocupação com o meio ambiente, sendo que os brasileiros expressaram maior intensidade nesta questão. O consumidor, por vezes, não associa suas ações do dia-a-dia com o ambiente mesmo havendo certa preocupação. Tais ações podem refletir no momento da compra, que pode estar relacionado com fatores internos e externos do consumidor sobre o consumo verde que influenciará o seu comportamento como um todo (ORZAN et al., 2018).

Conforme Tamashiro et al. (2013), as empresas devem divulgar mais as suas ações de responsabilidade socioambiental, sendo primordial além da abordagem a inovação, destacar para a opinião pública o enorme potencial das embalagens evidenciando os impactos positivos gerados para a biodiversidade e para a sociedade. Com intuito de esclarecer a importância das embalagens, que por vezes são consideradas inúteis para alguns consumidores (TAMASHIRO et al., 2013; KOENIG-LEWIS et al., 2014; LICCIARDELLO, 2017).

A modificação de atitudes e comportamentos ambientais requerem tempo, pois o consumidor procrastina nas transformações de hábitos mesmo já existindo consciência de que tem necessidade de mudança e sabe o que precisa ser feito. Este fato ocorre por não se correlacionar no ato da compra que a embalagem do produto, seja qual for, será descartada e virará resíduo. Dessa forma, há ausência de educação ambiental em relação ao ciclo de vida íntegro de cada produto e requerem estratégias singulares como educação ambiental e campanhas de sensibilização instrumentos regulares ou econômicos (NASCIMENTO et al., 2014; FERRAZ, 2015).

Por conseguinte, o consumo de produtos alimentares está associado à quantidade e qualidade das informações existentes na mente do consumidor, não somente por reposição ou obrigação, mas especialmente por identificação e valores (GONÇALVES et al., 2016). A maioria das pessoas associam embalagens ambientalmente amigáveis com o termo reciclagem, demonstrando um conhecimento inacabado e restrito do assunto (YOUNG, 2008). Além disso, o comportamento de reciclagem é voluntário e se encontra dependente dos valores e atitudes que os consumidores têm face aos resíduos e à reciclagem, já que são eles que deverão separar os resíduos de embalagem (FERRAZ, 2015). Segundo Nascimento et al. (2014), há uma transferência de responsabilidades em relação às consequências do descarte, quando os resíduos produzidos pelo consumidor deixam a sua residência, seja por conta do desconhecimento ou pela alienação, o problema passa a ser resolvido, inexistindo responsabilidade a partir dali.

O Instituto Brasileiro de Geografia e Estatística- IBGE demonstrou a média de produção física industrial do total de embalagens (de vidro, de metal, de madeira, de papel e papelão e de material plástico), desde 2012 até agosto de 2018, que respectivamente saltou de 97,3 para 103,6 que em números totalizam 1.084.815.260 de embalagens produzidas. Estas embalagens geram impactos ambientais e estão intimamente ligados ao desperdício de alimentos e geração de resíduos, e os responsáveis por mudanças massivas são os consumidores e suas atitudes frente a esse assunto. Portanto, é essencial saber os aspectos 
considerados pelo consumidor em relação às embalagens de alimentos no momento da compra, as suas percepções, práticas e conhecimentos sobre o assunto, a fim de provocar indagações sobre suas ações e promover melhoria que impactará nas empresas e modificará e/ou melhorará as estruturas já conhecidas do ciclo de vida das embalagens (ABRE, 2018; PLUMB et al., 2013; NORDIN et al., 2010).

Estudos mostraram que o consumidor ainda não vincula suas atitudes de consumo com as consequências seja no âmbito ambiental ou empresarial (ORZAN et al., 2018; NORDIN et al., 2010; LINDH et al., 2016; STEENIS et al., 2017). Esse fato está relacionado às características do consumidor e das embalagens. Além disso, associa-se a desinformação sobre o assunto ou não reconhecimento da importância das embalagens até a procrastinação de ações positivas. Essa afirmação leva em conta convicções que o consumidor já tem sobre como ele entende embalagens, o seu papel e percepção sobre sustentabilidade, que interferirá diretamente no processo de mudança, como também os aspectos da embalagem como, o preço, design, tipo de material, reciclabilidade até o rótulo e símbolos ambientais (ORZAN et al., 2018; NORDIN et al., 2010; LINDH et al., 2016; STEENIS et al., 2017). Segundo Orzan et al. (2018), para haver mudança é preciso que o consumidor reconheça as informações e se sinta motivado para realizar ações positivas, vendo o impacto por elas gerado. Estes mesmos autores relataram que muitas mudanças já aconteceram em empresas por conta da conscientização e alterações de consumo na busca por atender a demanda do consumo verde e estimular estas práticas.

\section{CONCLUSÕES}

As embalagens de alimentos são importantes pela função de proteção, acondicionamento, transporte e viabilização da distribuição, identificação e consumo. Os produtores e industrializadores de alimentos devem ser responsáveis pela escolha apropriada de embalagens de modo que estas cumpram seu papel tecnológico, mas que atendam a tendência de sustentabilidade em toda cadeia de produção. É essencial o estímulo a implementação de políticas públicas para permitir o consumo sustentável bem como promover a redução do descarte inadequado de embalagens. Além disso, é fundamental a educação de consumidores quanto às condutas ambientalmente amigáveis. Espera-se que, deste modo, seja estimulada a consciência de sustentabilidade dos produtos consumidos.

\section{REFERÊNCIAS}

ABEJÓN, R.; LASO, J.; MARGALLO, M.; ALDACO, R.; BLANCAALCUBILLA, G.; BALA, A.; PALMER, P. F.. Environmental impact assessment of the implementation of a DepositRefund System for packaging waste in Spain: A solution or an additional problem? Science of the Total Environment, v.721, n.137744, 2020. DOI: http://doi.org/10.1016/j.scitotenv.2020.137744

ABRELPE. Associação Brasileira de Empresas de Limpeza Pública e Resíduos Especiais. O Descaminhos do Lixo. ABRELPE, 2019.

ABRE. Associação Brasileira de Embalagens. Embalagens. São Paulo: ABRE, 2018.
ABRE. Associação Brasileira de Embalagens. Dados do setor: ano 2019. São Paulo: ABRE, 2019.

ABNT. Associação Brasileira de Normas Técnicas. NBR 10004: resíduos sólidos: classificação. Rio de Janeiro: ABNT, 2004.

BARÃO, M. Z.. Embalagens para produtos alimentícios: Dossiê Técnico. Curitiba: Instituto de Tecnologia do Paraná TECPAR, 2011.

BRASIL. 2010 Lei n. 12.305, de $\mathbf{2}$ de agosto de 2010. Política Nacional de Resíduos Sólidos Institui a Política Nacional de 
Resíduos Sólidos; altera a Lei no 9.605, de 12 de fevereiro de 1998; e dá outras providências. Brasília: DOU, 2010.

BRASIL. Ministério da Saúde. Resolução n. 91, de 11 de maio de 2001. Brasília: DOU, 2001.

BRASIL. Ministério do Meio Ambiente. Impacto das embalagens no meio ambiente. Brasília: MMA, 2018.

BRASIL. Ministério do Meio Ambiente. $\mathbf{O}$ que é embalagem. Brasília: MMA, 2018.

CABRAL, A. C. D.; CABRAL, A. C. B.. Gerenciamento sistêmico de embalagem em indústrias fabricantes de bens de consumo. Maturidade e Desafios da Engenharia de Produção. São Carlos, 2010.

CÔRTES, P. L.; DIAS, A. G.; FERNANDES, M. E. S. T.; PAMPLONA, J. M. V.. Comportamento ambiental: estudo comparativo entre estudantes brasileiros e portugueses. Ambiente \& Sociedade, São Paulo, v.19, n.3, p.111-134, 2016. DOI: http://doi.org/10.1590/18094422ASOC139099V1932016

DESHWAL, G. K.; PANJAGARI, N. R.; ALAM, T.. An overview of paper and paper-based food packaging materials: health safety and environmental concerns. Journal of Food Science and Technology, v.56, n.10, p.4391-4403, 2019. DOI: http://doi.org/10.1007/s13197-019-03950-z

DEBIAGI, F.; KOBAYASHI, R. K. T.; NAKAZATO, G.; PANAGIO, L. A.; MALI, S.. Biodegradable active packaging based on cassava bagasse, polyvinyl alcoholand essential oils. Industrial Crops and Products, v.52, p.664-670, 2014. DOI: http://doi.org/10.1016/j.indcrop.2013.11.032

DILUCIA, F.; LACIVITA, V.; CONTE A.; DEL NOBILE, M. A. Sustainable Use of Fruit and Vegetable By-Products to Enhance Food Packaging Performance. Foods, v.9, n.857, 2020. DOI: http://doi.org/10.3390/foods9070857

DONG, X.; LIU, S.; LI, H.; YANG, Z.; LIANG, S.; DENG, N.. Love of nature as a mediator between connectedness to nature and sustainable consumption behavior. Journal of Cleaner Production, v.242, 118451, 2020. DOI: http://doi.org/10.1016/j.jclepro.2019.118451

ECYCLE. Embalagens de alimentos e o desafio de reduzir a geração de resíduos. 2018.

EMF. Ellen Macarthur Foundation. The new plastics economy: Rethinking the future of plastics \& catalysing action. EMF, 2017.

FERRAZ, C. M. P.. Avaliação do conhecimento dos consumidores sobre os símbolos ambientais associados às embalagens. Dissertação (Mestrado em Engenharia do Ambiente) - Universidade Nova de Lisboa, Lisboa, 2015.

FELLOWS, P. J.. Tecnologia do processamento de alimentos: princípio e prática. 2 ed. São Paulo: Artmed, 2006.

FORTUNATI, E.; MAZZAGLIA, A.; BALESTRA, G. M. Sustainable control strategies for plant protection and food packaging sectors by natural substances and novel nanotechnological approaches. Journal of Science Food Agriculture, v.99, n.3, p.986-1000, 2019. DOI: http://doi.org/10.1002/isfa.9341

GONÇALVES, A. A.; PASSOS, M. G.; BIEDRZYCKI, A. Percepção do consumidor com relação à embalagem de alimentos: Tendências. Estudos Tecnológicos, v.4, n.3, p.271-283, 2008. DOI: http://doi.org/10.4013/ete.20083.10

GONÇALVES, P.; VARGAS, A.; FRÓES, R.. Percepções sobre consumo produto e embalagem de alimentos. Semioses, Rio de Janeiro, v.10, n.3, p.40-48, 2016.

GRUNERT, K. G.; HIEKE, S.; WILLS, J.. Sustainability labels on food products: Consumer motivation, understanding and use. Food Policy, v.44, p.177-189, 2014. DOI: http://doi.org/10.1016/j.foodpol.2013.12.001

JORGE, N.. Embalagens para alimentos. São Paulo: Cultura, 2013.

KARASKI, T. U.; RIBEIRO, F. M.; PEREIRA, B. R.; ARTEAGA, L. $P$.. Embalagem e sustentabilidade: desafios e orientações no contexto da economia circular. São Paulo: Verbus comunicação editorial, 2016.

KLAIMAN, K.; ORTEGA, D. L.; GARNACHE, C.. Consumer preferences and demand for packaging material and recyclability. Resources, Conservation and Recycling, v.115, p.1-8, 2016. DOI:

http://doi.org/10.1016/i.resconrec.2016.08.021

KOENIG-LEWIS, N.; PALMER, A.; DERMODY, J.; URBYE, A.. Consumers' evaluations of ecological packaging: rational and emotional approaches. Journal of Environmental Psychology, v.37, p.94-105, 2014. DOI: http://doi.org/10.1016/j.jenvp.2013.11.009

LANDIM, A. M.; BERNARDO, C. O.; MARTINS, I. B. A.; FRANCISCO, M. R.; SANTOS, M. B.; MELO, N. R.

Sustentabilidade quanto às embalagens de alimentos no Brasil. Polímeros, São Carlos, v.26, p.82-92, 2015. DOI: http://dx.doi.org/10.1590/0104-1428.1897

LAUTENSCHLAGER, B. I.. Avaliação de embalagem de consumo com base nos requisitos ergonômicos informacionais. Dissertação (Mestrado) - Universidade Federal de Santa Catarina, Florianópolis, 2001.

LICCIARDELLO, F.. Packaging, blessing in disguise. Review on its diverse contribution to food sustainability. Trends Food Science \& Technology, Roma, v.65, p.32-39, 2017. DOI: http://doi.org/10.1016/j.tifs.2017.05.003

LINDH, H.; OLSSON, A.; WILLIAMS, H.. Food packaging consumer perceptions: contributing to or counteracting environmentally sustainable development?. Packaging Technology and Science, v.29, p.3-23, 2016. DOI: http://doi.org/10.1002/pts.2184

MARSH, K.; BUGUSU, B.. Food Packaging: Roles, Materials, and Environmental Issues. Journal of Food Science, v.72, n.3, p.39-55, 2007. DOI: http://doi.org/10.1111/j.17503841.2007.00301.x

NASCIMENTO, L. F. M.; TREVISAN, M.; FIGUEIRÓ, P. S.; BOSSLE, M. B.. Do consumo ao descarte de produtos e embalagens: estamos alienados? Revista de Administração da Universidade Federal de Santa Maria, Santa Maria, v.7, 
n.1, p.33-48, 2014. DOI:

http://doi.org/10.5902/198346596298

ORZAN, G.; CRUCERU, A. F.; BĂLĂCEANU, C. T.; CHIVU, R.-G.. Consumers' behavior concerning sustainable packaging: an exploratory study on Romanian consumers. Sustainability, v.10, p.1-11, 2018. DOI: http://doi.org/10.3390/su10061787

PLUMB, A.; DOWNING, P.; PARRY, A.. Consumer attitudes to food waste and food packaging. Oxford: WRAP, 2013.

ROMANI, P. V.; PRENTICE-HERNÁNDEZ, C.; MARTINS, V. G.. Active and sustainable materials from rice starch, fish protein and oregano essential oil for food packaging. Industrial Crops and Products, v.97, p.268-274, 2017. DOI: http://doi.org/10.1016/j.indcrop.2016.12.026

SANGRONIZ, A.; ZHU, J.; TANG, X.; ETXEBERRIA, A.; CHEN, E. Y. X.; SARDON, H.. Packaging materials with desired mechanical and barrier properties and full chemical recyclability. Nature Communications, v.10, n.3559, 2019. DOI: http://doi.org/10.1038/s41467-019-11525-x

SIMON, B.; AMOR, M. B.; FÖLDÉNYI, R.. Life cycle impact assessment of beverage packaging systems: focus on the collection of post-consumer bottles. Journal of Cleaner Production, v.112, p.238-248, 2016. DOI: http://doi.org/10.1016/i.jclepro.2015.06.008

STEENIS, N. D.; HERPEN, E.; VAN DER LANS, I.; LIGHTARTM, T. N.; VAN TRIJP, H. C. M.. Consumer response to packaging design: The role of packaging materials and graphics in sustainability perceptions and product evaluations. Journal of Cleaner Production, v.162, p.286-298, 2017. DOI: http://doi.org/10.1016/j.jclepro.2017.06.036
TAMASHIRO, H. R. S.; MURARI, W. A.; OLIVEIRA, S. V. W. B.; ACEVEDO, C. R.. Comportamento socioambiental do consumidor: um estudo com universitários do interior paulista. Produção, São Paulo, v.22, n.2, p.201-212, 2012. DOI: http://doi.org/10.1590/S0103-65132012005000011

TSENG, M.; SUJANTO, R. Y.; IRANMANESH, M.; TANG, K.; CHIU, A. S.. Sustainable packaged food and beverage consumption transition in Indonesia: Persuasive communication to affect consumer behavior. Resources, Conservation \& Recycling, v.161, p.104933, 2020. DOI: http://doi.org/10.1016/j.resconrec.2020.104933

VERGHESE, K.; LEWIS, H.; LOCKREY, S.; WILLIAMS, H.. The role of packaging in minimising the food waste in the supply chain of the future. Centre for Design, RMIT University, 2013.

VITALE, G.; MOSNA, D.; BOTTANI, E.; MONTANARI, R.; VIGNALI, G.. Environmental impact of a new industrial process for the recovery and valorisation of packaging materials derived from packaged food waste. Sustainable Production and Consumption, v.14, n.105-121, 2018. DOI: http://doi.org/10.1016/i.spc.2018.02.001

YOUNG, S.. Packaging and the environment: A cross-cultura perspective. Design Management Review, p.42-48, 2008.

UNITED NATIONS. Sustainable development goal 12: Ensure sustainable consumption and production patterns. UNITED NATIONS, 2019.

WEF. World Economic Forum. The New Plastics Economy: Rethinking the Future of Plastics. WEF, 2016.

A CBPC - Companhia Brasileira de Produção Científica (CNPJ: 11.221.422/0001-03) detém os direitos materiais desta publicação. Os direitos referem-se à publicação do trabalho em qualquer parte do mundo, incluindo os direitos às renovações, expansões e disseminações da contribuição, bem como outros direitos subsidiários. Todos os trabalhos publicados eletronicamente poderão posteriormente ser publicados em coletâneas impressas sob coordenação da Sustenere Publishing, da Companhia Brasileira de Produção Científica e seus parceiros autorizados. Os (as) autores (as) preservam os direitos autorais, mas não têm permissão para a publicação da contribuição em outro meio, impresso ou digital, em português ou em tradução. 